\title{
Surto de Oestrus ovis em ovinos em Mato Grosso ${ }^{1}$
}

\author{
Diego Montagner Schenkel ${ }^{2}$, Mayda Karine Mendes Cavalcante ${ }^{2}$, Everson dos \\ Santos Damasceno ${ }^{2}$, Artur Kanadani Campos ${ }^{3}$ e Fernando Henrique Furlan ${ }^{3 *}$
}

\begin{abstract}
Schenkel D.M., Cavalcante M.K.M., Damasceno E.S., Campos A.K. \& Furlan F.H. 2012. [Outbreak of Oestrus ovis in sheep in Mato Grosso, Brazil.] Surto de Oestrus ovis em ovinos em Mato Grosso. Pesquisa Veterinária Brasileira 32(8):754-756. Laboratório de Patologia Animal, Hospital Veterinário, Campus Universitário de Sinop, Universidade Federal de Mato Grosso, Avenida Alexandre Ferronato 1200, Sinop, MT 78557-287, Brazil. E-mail: furlan@ufmt.br

Oestrus ovis is a cosmopolitan agent of myiasis in sheep and goats. The parasitic phase begins after adult females deposit first stage larvae into the nostrils of hosts. The aim of this study was to describe the epidemiological data, clinical signs, gross and microscopical findings of an outbreak of $O$. ovis myiasis in sheep in state of Mato Grosso. Sneezing and nasal discharges was the major clinical signs in infected sheep. The main gross findings include hyperemia and oedema of the nasal mucosa. At the microscopic exam there was moderate infiltration of mast cells and eosinophils in the nasal mucosa with moderate to severe oedema and hyperemia. Although affecting a large number of sheep, the mortality occurred due to other causes such as Haemonchus contortus infection and pneumonia.
\end{abstract}

INDEX TERMS: Diseases of sheep, Oestrus ovis, myiasis, head worm.

\begin{abstract}
RESUMO.- Oestrus ovis é um parasito cosmopolita que pode acometer ovinos e caprinos. A fase parasitária inicia-se após as fêmeas adultas depositarem suas larvas nas narinas dos hospedeiros. 0 objetivo deste trabalho foi de descrever os aspectos clínicos, epidemiológicos, macroscópicos e microscópicos de um surto de oestrose em ovinos no estado de Mato Grosso. Os principais sinais clínicos observados foram espirros e descarga nasal. Macroscopicamente havia hiperemia e edema da mucosa nasal. Os achados microscópicos eram caracterizados por hiperemia e edema moderado a acentuado e difuso, associados a infiltrado leve a moderado predominante de mastócitos e eosinófilos na submucosa. Embora a doença fosse observada em um grande número de animais a mortalidade observada nos surtos ocorreu devido à infestação por Haemonchus contortus e pneumonia.
\end{abstract}

TERMOS DE INDEXAÇÃO: Doenças de ovelhas, Oestrus ovis, miíases, verme da cabeça.

\footnotetext{
${ }^{1}$ Recebido em 9 de março de 2012.

Aceito para publicação em 23 de abril de 2012.

${ }^{2}$ Graduando, Instituto de Ciências da Saúde, Campus Universitário de Sinop, Universidade Federal de Mato Grosso (UFMT), Av Alexandre Ferronato 1200 , Sinop, MT 78557-28, Brasil.

${ }^{3}$ Laboratório de Patologia Animal, Hospital Veterinário, Universidade Federal de Mato Grosso, Campus Universitário de Sinop, Sinop, MT. *Autor para correspondência: furlan@ufmt.br
}

\section{INTRODUÇÃO}

As doenças causadas por parasitos são importantes causas de prejuízos na produção nacional de ovinos (Rissi et al. 2010). A oestrose (bicho da cabeça, falso torneio) é uma doença que pode acometer ovinos e é causada pela infestação de larvas de Oestrus ovis na cavidade nasal e seios nasais desses animais (Tabouret et al. 2001). As fêmeas adultas de O. ovis fazem a deposição de larvas nas narinas dos animais e essas larvas dirigem-se rapidamente aos cornetos nasais e frontais, completando o período de parasitismo entre 1 e 9 meses (Yilma \& Dorchies 1991) dependendo das condições climáticas. As moscas adultas perturbam os animais que tentam se livrar delas sacudindo a cabeça, esfregando-a contra objetos ou outros animais, ou se coçando e batendo com os membros anteriores. Os animais apresentam respiração dificultosa e ruidosa. No seio frontal e meato dos cornetos nasais a larva causa irritação da mucosa levando a rinite catarral com espirros e/ou corrimento nasal purulento (Taylor et al. 2011).

Apesar de $O$. ovis ser considerada cosmopolita, ocorrendo em todas as regiões do globo onde existam ovinos e caprinos (Ribeiro 2007), não existe registro na literatura da ocorrência dessa doença no Estado de Mato Grosso. 0 objetivo deste trabalho foi descrever aspectos clínicos, epidemiológicos, macroscópicos e microscópicos de um surto de oestrose em ovinos em Mato Grosso. 


\section{MATERIAL E MÉTODOS}

A doença foi diagnosticada em duas propriedades, localizadas no município de Sinop (propriedade A - $12^{\circ} 00^{\prime} 34^{\prime \prime}$ S e $55^{\circ} 25^{\prime} 41^{\prime \prime}$ 0; propriedade B - $12^{\circ} 00^{\prime} 34^{\prime \prime}$ S e longitude $55^{\circ} 25^{\prime} 41^{\prime \prime}$ ) e uma no município de Matupá, (propriedade C - $10^{\circ} 05^{\prime} 82^{\prime \prime} \mathrm{S}$ e $54^{\circ} 90^{\prime} 72^{\prime \prime}$ 0) região norte de Mato Grosso. A propriedade A possuía um rebanho de 1800 ovinos mestiços Santa Inês mantidos em um piquete de 200 hectares formado por Brachiariabrizantha, onde havia 1250 ovinos clinicamente doentes, sendo que deste 28 morreram e 2 foram necropsiados (ovinos 1 e 2). Na propriedade B havia 80 ovinos mestiços Santa Inês, mantidos em uma área de 50 hectares de pastagem formadas por Cynodon nlemfuensis, a doença acometia todos os animais sendo que destes, nove morreram e dois ovinos doentes foram sacrificados e necropsiados (ovinos 3 e 4). $\mathrm{Na}$ propriedade $\mathrm{C}$ havia 20 ovinos mantidos em um piquete de cinco hectares formados por Brachiaria brizantha. Nessa propriedade havia 15 animais doentes, sendo que desses sete morreram e dois foram necropsiados (Ovinos 5 e 6). .Amostras de tecidos foram coletadas em formol 10\%, processadas rotineiramente para confecção de lâminas histológicas e coradas pela técnica de hematoxilina e eosina. Amostras para exame bacteriológico foram coletadas em frascos estéreis, semeados em Agar sangue, cultivadas por 24-48 horas a $37^{\circ} \mathrm{C}$ e submetidas a testes bioquímicos para identificação das bactérias. Larvas encontradas na cavidade nasal e nos seios paranasais foram coletadas em formol $10 \%$ e identificadas seguindo os critérios de Zumpt 1965 e Guimarães \& Papavero (1999).

\section{RESULTADOS}

Na propriedade A, a oestrose ocorreu entre os meses de Abril e maio de 2009, sem preferência por idade ou sexo. Clinicamente os animais apresentavam espirros, inquietação, movimentação excessiva da cabeça para cima e para baixo, secreção nasal catarral, respiração ruidosa e as vezes abdominal. Os animais que morreram além dos sinais descritos apresentavam aumento de volume submandibular, abaulamento do abdômen, palidez de mucosas, cansaço, apatia e morte. À necropsia havia edema submandibular, palidez generalizada de vísceras e grande quantidade de larvas de Haemonchus sp. no abomaso. No seio nasal havia hiperemia e edema da mucosa e grande quantidade de larvas de Oestrus ovis (Fig.1).

Na propriedade B a doença ocorreu em Abril de 2011. Os animais haviam sido adquiridos há 1 mês de uma outra propriedade e alguns animais já apresentavam os sinais da doença. Adoeceram ovinos de todas as idades e sexos. Inicialmente apenas alguns animais apresentavam espirros e secreção catarral, depois de 3 semanas a doença espalhou-se para os demais. Observou-se espirros, inquietação, movimentação excessiva da cabeça para cima e para baixo, secreção nasal catarral, respiração ruidosa e as vezes abdominal e em alguns ovinos havia palidez de mucosas. À necropsia havia palidez generalizada de vísceras, grande quantidade de larvas de Haemonchus sp'. no abomaso e grande quantidade de larvas de $O$. ovis nos seios nasais que se apresentavam com mucosa espessa e hiperêmica.

Os animais da propriedade $C$ apresentaram a doença em Maio de 2011. Clinicamente observou-se dispnéia grave com respiração abdominal e secreção nasal catarro-purulenta. À auscultação havia estertor na região crânio ventral pulmonar. Alguns animais apresentavam também espirros, inquietação, movimentação excessiva da cabeça para cima e para baixo e secreção nasal catarral. Na necropsia observou-se secreção purulenta nos seios nasais, bem como grande quantidade de larvas de $O$. ovis. 0 pulmão apresentava-se com consolidação crânio-ventral de lobos apicais e diafragmáticos totalizando $60 \%$ da área pulmonar. Ao exame histológico havia, no pulmão, infiltrado acentuado difuso de neutrófilos em brônquios, bronquíolos e alvéolos associado a edema acentuado difuso. 0 exame bacteriológico apresentou crescimento negativo em ágar sangue.

Dentre as larvas coletadas, havia larvas de segundo e terceiro estágios de evolução. Algumas destas larvas apresentavam-se danificadas, não permitindo sua identificação, entretanto, todas as larvas identificadas pertenciam à espécie $O$. ovis.

Ao exame histológico da cavidade nasal dos animais parasitados por 0 . ovis havia hiperemia e edema moderado a acentuado difuso associados a infiltrado leve a moderado predominante de mastócitos e eosinófilos na submucosa (Fig.2). Adicionalmente observou-se em todos os animais hiperplasia leve a moderada de células secretoras de muco.

Procedeu-se tratamento com ivermectina em todas as propriedades devido ao diagnóstico de oestrose. Levamisol

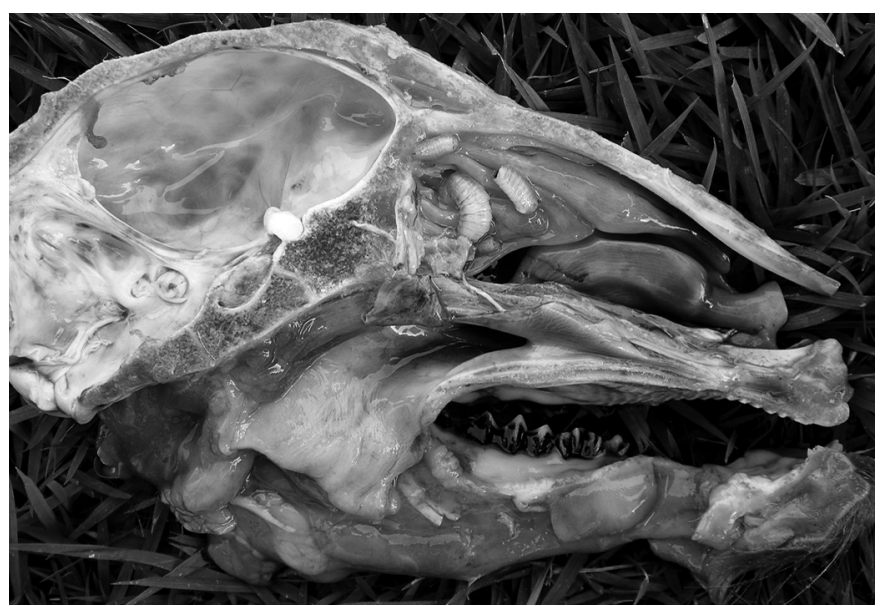

Fig.1. Corte sagital da cabeça do Ovino 2 apresentando hiperemia e larvas de Oestrus ovis nas conchas nasais.

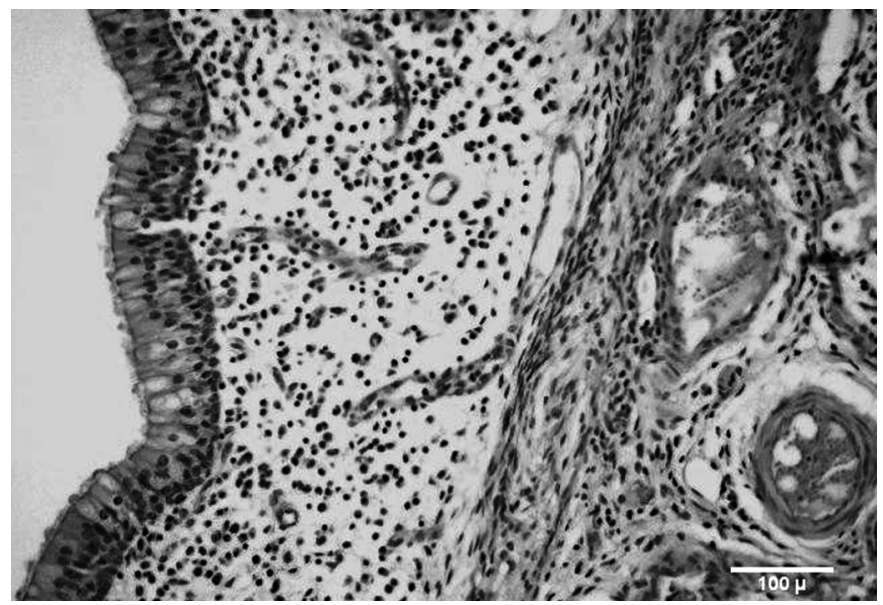

Fig.2. Ovino infestado por Oestrus ovis. Concha nasal do Ovino 1 onde se observa infiltrado inflamatório acentuado difuso e edema moderado. HE, 20x. 
foi utilizado nas propriedades A e B, pois os animais além de oestrose apresentavam também hemoncose e penicilina foi o tratamento de escolha na propriedade $\mathrm{C}$ para combater a pneumonia que ocorria juntamente com a oestrose. Após o tratamento não houve mais mortes nas propriedades.

\section{DISCUSSÃO}

O diagnóstico de parasitismo por Oestrus ovis baseou-se nos sinais clínicos e presença do parasito no seio nasal dos ovinos doentes. Embora a doença apresente alta prevalência (Alem et al. 2010, Garcia et al. 2010), como verificado no caso estudado onde variou entre $69 \%$ a $100 \%$, a mortalidade é baixa e ocorre geralmente devido á infecções secundárias (Ribeiro 2007). Nos surtos estudados as mortes ocorreram nas propriedades A e B por hemoncose devido a grande quantidade de parasitos no abomaso. Na propriedade $\mathrm{C}$, devido as lesões macroscópicas, microscópicas e ausência de crescimento bacteriano em Agar sangue, a morte foi atribuída a broncopneumonia catarral por Mycoplasma sp. Micoplasmas são microorganismos fastigiosos e exigem meios bastante ricos, motivo pelo qual não crescem em meios comuns (Buzinhani et al. 2007).

Em Mato Grosso não havia relatos anteriores sobre oestrose. No Brasil, a ocorrência desta doença era mais comum nas regiões Sudeste e Sul devido às características climáticas destas regiões e principalmente a abundante criação de ovinos, entretanto Guimarães \& Papavero (1999), relatam que a ocorrência deste parasito em novas áreas, pode estar relacionada à expansão da pecuária ovina e caprina para novas regiões do país, hipótese sustentada também por Cansi et al. (2011) que relata, pela primeira vez, a ocorrência deste díptero no Distrito Federal.

Os sinais clínicos verificados estão em acordo com os descritos na literatura e ocorrem devido à irritação da mucosa causada pela larva e, principalmente, pela atividade das moscas adultas. Quando elas abordam o ovino para depositar as larvas desencadeiam no animal alterações características de comportamento como pressionar a cabeça contra a lã de outras ovelhas, solo ou capim, sacudir a cabeça e bater os pés (Ribeiro 2007, Taylor et al. 2010). Podem ocorrer vários ataques a cada dia, de forma que 0 animal pode parar de se alimentar e perder peso (Taylor et al. 2010).

As lesões causadas por 0 . ovis são de modo geral brandas, como observou-se nos casos estudados. Isso se deve em resposta ao estímulo do movimento larvário e não ao fato de as larvas alimentam-se do muco secretado e de tecido da mucosa. As lesões histológicas verificadas na cavidade nasal dos ovinos doentes devem-se: ao trauma mecânico causado pelas larvas, uma vez que as mesmas aderem-se à mucosa utilizando ganchos orais e, principalmente à reação de hipersensibilidade provocada por moléculas secretadas/excretadas pela larva das quais os antígenos salivares são os mais importantes frente ao sistema imune do hospedeiro (Taylor et al. 2010, Angulo-Valadez et al. 2011). As larvas permanecem nas vias nasais por período variável, oscilando de 2 semanas no verão até 9 meses durante as estações mais frias. Após atingir a idade adulta, as fêmeas sobrevivem apenas por duas semanas, mas durante esse tempo podem depositar até 500 larvas. No estado de Mato Grosso, devido ao clima quente, provavelmente as larvas são ativas o ano todo, possibilitando a ocorrência de duas ou três gerações de modo que o tratamento deve ser realizado no período em que grande parte da população estará em fase larval, quando o tratamento será mais efetivo. Ribeiro (2007) propõe para a região centro-oeste, o tratamento dos animais infestados, no final da estação seca ou início da estação chuvosa e ao final desta última. No entanto, os estudos sobre a ocorrência deste parasito no estado de Mato Grosso são incipientes. Assim, futuros estudos epidemiológicos sobre a oestrose no estado de Mato Grosso são importantes para se estabelecer medidas de controle e tratamento mais efetivas.

\section{CONCLUSÃO}

A oestrose ocorre no estado de Mato Grosso e a associação com outras doenças pode levar a altas taxas de mortalidade nos ovinos.

Agradecimentos.- À Coordenação de extensão da Universidade Federal de Mato Grosso pelo apoio às atividades de extensão e à Fundação de Amparo a Pesquisa do Estado de Mato Grosso pelo apoio financeiro.

\section{REFERÊNCIAS}

Alcaide M., Reina D., Frontera E. \& Navarrete I. 2005. Analysis of larval antigens of Oestrus ovis for the diagnosis of oestrosis by enzyme-linked immunosorbent assay. Med. Vet. Entomol. 19(2):151-157.

Alem F., Kumsa B. \& Degefu H. 2010. Oestrus ovis larval myiasis among sheep and goats in Central Oromia, Ethiopia. Trop. Anim. Prod. 42(4): 697-703.

Angulo-Veladez C.E., Ascencio F., Jacquiet P., Dorchies P. \& Cepeda-Palacios R. 2011. Sheep and goat immune responses to nose bot infestation: A review. Med. Vet. Entomol. 25(2):117-125.

Buzinhani M., Metiffogo E. \& Timenetsky J. 2007. Detecção de Mycoplasma spp. e Ureaplasma diversum em vacas com distúrbios reprodutivos. Arq. Bras. Med. Vet. Zootec. 59(6):1368-1375.

Cansi E.R., Castro M.B., Mustafa V.S., Porto M.R. \& Borges J.R. 2011. Ovis aries (Artiodactyla: Bovidae) e Capra hircus (Artiodactyla: Bovidae) parasitados por Oestrus ovis (Diptera: Oestridae) no Distrito Federal, Brasil. Entomo Brasilis 4:147-149.

Garcia M.J., Lucientes J., Peribáñez M.A., Castillo J.A., Calvete C. \& Ferrer L.M. 2009. Epidemiology of Oestrus ovis infection of sheep in northeast Spain (mid-Ebro Valley). Trop. Anim. Prod. 42(5):811-813.

Guimarães J.H. \& Papavero N. 1999. Myiasis in man and animals in the Neotropical Region. Bibliographic database. Editora Plêiade/Fapesp, São Paulo. 308p.

Ribeiro P.B. 2007. Mí́ases, p.551-564. In: Riet-Correa F., Schild A.L., Lemos R.A.A. \& Borges J.R.J. (Eds), Doenças dos Ruminantes e Eqüinos. $3^{\mathrm{a}}$ ed. Palloti, Santa Maria.

Rissi D.R., Pierezan F., Oliveira Filho J.C., Fighera R.A., Irigoyen L.F., Kommers G.D. \& Barros C.S.L. 2010. Doenças de ovinos da região central do Rio Grande do Sul: 361 casos. Pesq. Vet. Bras. (30)1:21-28.

Tabouret G., Jacquiet P., Scholl P. \& Dorchies P. 2001. Review Oestrus ovis in sheep: Relative third-instar populations, risks of infection and parasitic control. Vet. Res. 32(6):525-31.

Taylor M.A., Coop R.L. \& Wall R.L. 2010. Parasitologia Veterinária. 3로 ed. Guanabara Koogan, Rio de Janeiro. 768p.

Yilma J.M. \& Dorchies P. 1991 Epidemiology of Oestrus ovis in southwest France. Vet. Parasitol. 40:315-323.

Zumpt F. 1965. Myiasis in Man and Animals in the Old World. Butterworts, London. 267p. 